\title{
Nazogastrik Tüp Uygulama Öğretiminde Yenilikçi Bir Yaklaşım: NAZO-AR
}

\author{
Merdiye ŞENDİR ${ }^{1}$, Hamiyet KIZIL ${ }^{2}$
}

\section{ÖZ}

Geleneksel yöntem ve teknolojilere göre avantaj sağlaması, eğitimi desteklemeye ve zenginleștirmeye yönelik etkili yöntem ve ortam arayışına cevap vermesi açısından eğitimde artırılmış gerçeklik ve sanal gerçeklik kavramları ön plana çıkmaktadır. Artırılmış gerçeklik teknolojisi, çeşitli uygulamalar aracılı̆̆ıyla insanların gerçek dünya ortamı üzerine yerleştirilen sanal nesneler ile etkileşime geçtikleri ortamlardır. Sanal Gerçeklik ise; katılımcılarına gerçekmiş hissi veren, bilgisayarlar tarafından yaratılan dinamik bir ortamla karşılıklı iletişim olanağı tanıyan, üç boyutlu bir benzetim modelidir. Günümüzde hemşirelik eğitim gereksinimlerinin değişmesi, klinik uygulamaların azalması, öğrenci sayısının fazla olması ve öğretim elemanı sayısının yetersiz olması sebebiyle ileri teknoloji içeren simülasyonlar ve dokunma hissini veren haptik cihaz ile donatılar hemşirelik eğitiminde yaygınlaşmaktadır. Bu makalede, yenilikçi öğretim metotlarından olan sanal ve artırılmış gerçeklik teknolojisi ile araştırmacılar tarafından geliştirilmekte olan "Nazogastrik Tüp Uygulama Öğretiminde Haptik Kontrollü Artırılmış Gerçeklik Simülasyon” hakkında bilgi paylaşımı amaçlanmıştır. Elektronik ortamda gerçekleştirilecek Nazogastrik Tüp-NGT beceri uygulaması öğrencinin, hayati önem taşıyan bir aktivitede, gerçek ortamdaymış gibi hissederek risk almadan yapay veya sanal deneyim kazanacağı ve teknolojiyi kullanma becerisini geliştireceği bir öğrenme ortamı yaşamasını sağlayacaktır. Bu bağlamda, eğitimde simülasyon kullanımının arttırılması ve hemşirelik uygulamalarının simülasyona temellendirilmesi önerilmektedir. Geliştirmekte olduğumuz programımızla hemşirelik eğitimine inovatif bir öğretim metodu kazandırarak öğrencilerin teknoloji ile donatılması hedeflenmektedir.

Anahtar Kelimeler: Hemşirelik eğitimi; nazogastrik tüp; simülasyon; inovasyon; sanal gerçeklik; artırılmış gerçeklik.

\section{Innovative Approach in Nasogastric Drug Practice Teaching: NAZO-AR}

\begin{abstract}
The concepts of augmented reality and virtual reality come into prominence in order to provide an advantage over traditional methods and technologies and to respond to the search for effective methods and environment to support and enrich education. Augmented reality technology is the environment in which people interact with virtual objects placed on a real-world environment through a variety of applications. Virtual Reality is a three-dimensional simulation model that gives the participants a real feeling and provides mutual communication with a dynamic environment created by computers. Nowadays change of nursing education requirement, decreased clinical practice, having a greater number of students and inadequate number of educators so advanced technology simulations and haptic devices with accessories that provide a sense of touch are becoming prevalent in nursing education. In this article, it was aimed to share information about virtual and augmented reality technology that are innovative teaching methods and also "Haptic Controlled Augmented Reality Simulation in Nasogastric Drug Practices Teaching” developed by researchers. The Nasogastric Drug-NGT skills implementation in the electronic environment will enable to live in the learning environment which student feels like a real world and gain artificial or virtual experience without risk in a vital activity and develop the ability to use the technology. In this context, it is proposed to increase the use of simulation in education and to base nursing applications on simulation. It is aimed to equip the students with technology by giving an innovative teaching method to nursing education with our program that we are developing.
\end{abstract}

Keywords: Nursing education; nasogastric tube; simulation; innovation; virtual reality; augmented reality.

1 Sağlık Bilimleri Üniversitesi, Hemşirelik Fakültesi, Hemşirelik Esasları A.D., İstanbul, Türkiye

2 Beykent Üniversitesi, Sağlık Bilimleri Yüksekokulu, Hemşirelik Bölümü, İstanbul, Türkiye

Sorumlu Yazar / Corresponding Author: Hamiyet KIZIL, e-mail: hamiyetkizil@gmail.com Geliş Tarihi / Received: 11.07.2018, Kabul Tarihi / Accepted: 04.03.2019 


\section{GíRiş}

Nazogastrik tüpler (NGT); tanısal, koruyucu, tedavi edici amaçlarla mide veya bağırsağa burun yoluyla yerleştirilen tek veya çift lümenli esnek sondalardır. Kısa süreli kullanım için ağızdan da (orogastrik) yerleştirmek mümkündür. NGT insanlarda ilk kez 17. yüzyılda Aquapedente tarafindan beslenme amaciyla, 1884'te Kussmaul tarafindan dekompresyon amaciyla kullanılmıştır. Günümüzde ise; ileus veya bağırsak obstrüksiyonu tedavisi, ilaç uygulaması, enteral beslenme, mide içeriğinin aspirasyonunu sağlama, midede herhangi bir sebeple biriken sıvı ve gazı çıkararak gerilimi önleme, mide lavajı, mide kanamalarında drenajı sağlama, travma hastalarında gastrointestinal yaralanmayı değerlendirme, bilinci kapalı hastada aspirasyonu önleme amaçlarıyla uygulanmaktadır $(1,2)$.

NGT uygulamasında, tüpün doğru yerleştirilmesi hayati önem taşıyan bir konudur. NGT'nin uygulaması sırasında, tüpün yanlışlıkla piriform sinüse, beyine, yemek borusuna, peritona, bağırsaklara ve solunum yollarına yerleştirilebildiği bildirilmektedir $(3,4)$. NGT uygulamasına bağlı olarak, pulmoner aspirasyon gibi solunum yolu komplikasyonları ve tüpten kaynaklanan tüpün tıkanması, nazofarenkste travma gibi komplikasyonların yanı sıra, trakeaobronşial girişim kazası sonrasında pnömotoraks, plevral effüzyon, apse, ampiyem gibi komplikasyonlar da görülebilmekte ve bu komplikasyonlar ölümle sonuçlanabilmektedir $(2,5,6)$.

Sağlık bakım kurumlarında sıklıkla uygulanan NGT işlemi "19 Nisan 2011 tarihli Hemşirelik Yönetmeliği'nde” hemşirenin görev, yetki ve sorumlulukları arasında belirtilmiştir (7). NGT bakımında ağız, burun ve tüp bakımı önemli bir yer tutmaktadır. Nazogastrik tüpün takılması, tespit edilmesi, kayıt edilmesi ve tüpü olan hastaların bakımı hemşirenin sorumluluğu altındadır. Ayrıca Nazogastrik tüp ile hastaya ilaç uygulanacaksa aspirasyon riskini ve reflüyü önlemek için hastanın başının $30^{\circ}-45^{\circ}$ yükseltilmesi, ilaç uygulaması sonrası tüpün yıkanarak tıkanıklıkların önlenmesi, tespit bantların cilde zarar vermemek için düzenli olarak değiştirilmesi ve nazogastrik tüpün kullanılmasına ihtiyaç kalmadığında tüpü takmak gibi çıkarmak da hemşirenin sorumluluğundadır (8).

Böylesine önemli ve komplike bir uygulamanın sorumluluğunu almak için NGT becerisinin iyi öğretilmesi gerekmektedir. Hemşirelik Ulusal Çekirdek Eğitim Programı'nda (HUÇEP) yer alan "NG sonda yerleştirme ve bakım" becerisi hemşirelik eğitiminde yer alan önemli uygulamalardandır. NGT becerisinin kazandırılmasında geçmişten günümüze farklı öğretim metotları kullanılmıştır. İlerleyen teknoloji ile birlikte geleneksel öğretim yöntemlerinden yenilikçi öğretim metotlarına geçiş yapılmıştır (9).

Bu makalede, yenilikçi öğretim metotlarından olan sanal gerçeklik (Virtual Reality-VR) artırılmış gerçeklik (Augmented Reality-AR) teknolojisi ile araştırmacılar tarafindan geliştirilmekte olan "Nazogastrik Tüp Uygulama Öğretiminde Haptik Kontrollü Arttırılmış Gerçeklik Simülasyon" hakkında bilgi paylaşımı amaçlanmıştır. Elektronik ortamda gerçekleştirilecek NGT beceri uygulaması öğrencinin, hayati önem taşıyan bir aktivitede, gerçek ortamdaymış gibi hissederek risk almadan yapay veya sanal deneyim kazanacağı ve teknolojiyi kullanma becerisini geliştireceği bir öğrenme ortamı yaşamasını sağlayacaktır.

\section{Dünyada ve Türkiye'de Nazogastrik Tüp Uygulama Öğretiminde Yenilikçi Yaklaşımlar}

Günümüzde dünyanın her yerinde yükseköğretim programları, gelişen teknolojiye ayak uydurmak ve yenilikçi bireyler yetiştirmek için yenilikçi stratejiler uygulayarak eğitim kapasitelerini arttırmaya çalışmaktadırlar. Hemşirelikte de akademisyenler, yenilikçi kültürünü oluşturmak için mevcut eğitim sisteminde köklü değişikliklerin gerekli olduğunu bildirmektedir (10,11). Eğitimde yenilikçi uygulamaların kullanılması, eğitimcilerinin hemşirelik öğrencilerini mevcut klinik ortamlarına hazırlamasını sağlamaktadır $(11,12)$. Klinik uygulamalara adaptasyonu sağlamak ve kliniklerde yaşanılabilecek sorunları ortadan kaldırmak için hemşirelik eğitiminde simülasyon uygulamaları zamanla yaygınlaşmış ve benimsenmiştir (13). Kim Young ve arkadaşlarının (14) hemşirelik uygulamalarında simülasyona dayalı eğitimin iletişim becerisi ve klinik yeterlilik üzerine etkileri adlı çalışmalarında, simülasyona dayalı eğitimi alan deney grubunun üyeleri, kontrol grubuna göre anlamlı derecede daha yüksek iletişim becerisi ve klinik yeterlilik puanları gösterdiği belirtilmiştir. Leonard ve arkadaşlarının (15) hemşirelik öğrencilerinin profesyoneller arası takım eğitiminde yüksek gerçeklikli simülasyonu kullanılmasını algılaması adlı çalışmasında, simülasyona dayalı profesyoneller arası eğitim deneyimlerinin üçüncü ve dördüncü sınıf hemşirelik öğrencileri için zengin öğrenme firsatları sağladığını göstermektedir. Cordeau (16) hemşirelik öğrencilerinin klinik simülasyonunun yaşanmış deneyimi adlı çalışmasında, öğrencilerin bireysel klinik simülasyonlarını tasarlarken, uygularken ve değerlendirirken klinik simülasyonun algılarını ve anlamlarını anlama yoluyla, bu öğretim / öğrenme stratejisi öğrenci ihtiyaçlarını ve öğrenme çıktılarını daha iyi karşılayacağı belirtilmiştir. Gelişen eğitim stratejileriyle birlikte teknoloji çağında doğmuş ve büyümüş olan dijital neslin değişen beklentilerini karşılamak için hemşirelik eğitiminde yenilikçi yaklaşımlar olan AR ve VR uygulamaları yaygınlaşmaktadır $(17,18)$.

İnsanların sanal ortamı tüm duyularla deneyimlemesi ile yapay bir dünyada olduğu gerçeğini unuttuğu durum olarak tanımlanan sanal gerçeklik, bilgisayar ortamında oluşturulan resim ve animasyonların kişilerin zihninde gerçeklik hissi oluşturulmasını sağlayan üst düzey teknolojiye sahiptir $(19,20)$. Sanal gerçeklik uygulamaları bu teknolojik özellikleri sayesinde risksiz bir ortamda hemşirelik uygulama becerilerine izin vererek öğrencinin kaygısını azaltmaya, kendine olan güvenini geliştirmeye ve klinik karar verme becerilerinin gelişmesine katkıda bulunmaktadır (9,21). Vidal ve arkadaşlarının (22) flebotomi eğitimi üzerine yapmış oldukları çalışmada sanal gerçeklik simülatörüyle eğitim alan öğrencilerin "ağrı faktörü, hematom oluşumu ve yeniden yerleştirme sayısı" ölçümlerinde daha iyi performans gösterdikleri belirtilmiştir. Choi ve ark. (9) çalışmalarında NGT yerleştirme becerilerinin öğretimini geliştirmek için geliştirilmiş VR tabanlı bir eğitim simülasyon sistemi sunmuşlardır. $\mathrm{Bu}$ çalışmalarında; NGT beceri uygulamasının klinik öğretimi ve probleme dayalı 
öğrenmede uygulanmasını kolaylaştırmak için, sistemin başarısız ve zorlu durumlarını öğrencinin karşısına çıkartan çalışmaların yapılması önerilmiştir. Chiang ve ark. (23), çalışmalarında NGT uygulamasının öğretiminde haptik sistem ve geleneksel yöntem karşılaştırmış olup sanal gerçek tabanlı haptik sistemin etkin olduğunu bildirmişlerdir. Çalışma sonuçlarına göre uygulamanın büyük örneklemlerle tekrarlanması önerilmiştir.

Gerçek dünyadaki fiziksel ortamı, bilgisayar aracılığıyla oluşturulan duyusal girdilerle canlı, dinamik ve gerçek zamanlı olarak hissedip yaşamamızı sağlayan artırılmış gerçeklik de yenilikçi eğitim yöntemleri arasında yer almaktadır (24,25). Carlson \& Gagnon (26), artırılmış gerçeklik ve oyun temelli yerleşik öğrenme teorisi ile simülasyon kavramlarını (ARISE) birleştirdikleri çalışmalarında; hemşirelikte eğitim uygulamalarının daha özgün ve ilgi çekici bir deneyim haline getirerek öğrenmeyi ve eleştirel düşünmeyi geliştirebileceğini vurgulamışlardır. Aebersold ve ark. (27), NGT uygulama becerisini artırılmış gerçeklik teknolojisi ile donatarak mobil uygulamaya çevirdikleri çalışmalarında, öğrencilere sınıf ortamına bağlı kalmaksızın verdikleri mobil eğitim sayesinde geleneksel yöntemden daha etkin ve kalıcı ögrenme sağladıklarını belirtmişlerdir.

Yenilikçi eğitim yöntemlerinden olan mobil uygulamalar da öğrenimi kolaylaştırmaktadır. Özel Erkan (12), web tabanlı hemşirelik tanıları mobil öğrenme sistemi adlı tez çalışmasında öğrenciler için karmaşık ve zor olan hemşirelik tanılarını teknolojiyi kullanarak kolay ve keyifli hale getirmiştir. Karadağ ve arkadaşlarının (13) çalışmasında, öğrenciler geleneksel eğitim yöntemleri yerine yüksek teknoloji içeren simülasyon uygulamalarının daha etkin ve kalıcı öğrenme sağladığını belirtmişlerdir. Dünya literatüründe yer alan ve kullanılan bu yenilikçi eğitim teknolojilerinin ülkemizde kullanımı sınırlıdır. Baş döndüren hızla gelişen teknolojiye kayıtsız kalmayıp hemşirelik eğitim ve uygulamalarına teknolojiyi entegre ederek yenilikçi hemşireler yetiştirmek mesleğimizin ayak seslerini yükseltecektir.

Nazogastrik Tüp Uygulama Öğretiminde Haptik Kontrollü Artırılmış Gerçeklik Simülasyon Programı Nazogastrik tüp yerleştirme, temel hemşirelik uygulamalarındandır. Doğru ve yerinde uygulandığında hayat kurtarabilen, yanlış uygulandığında ise ölümle sonuçlanabilen invaziv bir girişimdir. Hemşirelik birinci sınıfında öğretimine başlanan NGT uygulama becerisini etkin kılmak ve dijital nesil adıyla anılan yeni neslin dikkatini çekerek öğretimin kalıcı olmasını sağlamak için bütün alanlarda olduğu gibi hemşirelikte de bilişim teknolojilerinin aktif kullanılması gerekmektedir.

Mevcut sistemde hemşirelik öğrencilerine sınıf ortamında verilen becerinin teorisinin ardından laboratuvarda maketler üzerinde becerinin gösterilmesi yapılmaktadır. Komplike bir girişim olduğundan dolayı da hemşirelik eğitiminin üçüncü ayağı olan klinik uygulamalarda öğrencinin yapmasına çoğu zaman izin verilmemektedir. $\mathrm{Bu}$ durumda öğrenci beceriyi tam anlamiyla geliştiremeyip mezun olduğunda gerçekliğini hissetmediği bir uygulamayı yapmak zorunda kalmaktadır. Ayrıca yaşamsal bir öneme sahip ilaç uygulaması sonrasında yaşanabilecek sorunlar ve bu durum karşısında problem çözme becerisi öğrencilere kazandırılamamaktadır. Bilişim teknolojilerinin hayatımıza girmesi sayesinde ileri teknoloji içeren simülasyonlar ile eğitim birlikteliği sağlanmış olup sanal nesne ve ortamların gerçek dünya gibi yansıtılmasının yanında dokunma hissini de veren haptik cihazlar ve donatılar gündeme gelmiştir. Yapılan çalışmalarla geleneksel yönteme göre etkinliği kanıtlanmış olan haptik cihaz ve bilgisayar ekranı, gerçek bir NGT yerleşimindeki ayardan farklı olarak bir masaüstünde yan yana yerleştirilmiştir. $\mathrm{Bu}$ durum haptik cihaz ve dolayısıyla kullanıcının elinin göz temasından uzak kalmasına sebep olarak uygulamanın başarısını ve gerçekçiliğini azaltmaktadır (9).

Literatüre göre, elektronik ortamda gerçekleştirilecek NGT beceri uygulamasının öğrencinin risk almadan deneyim kazanacağı ve teknolojiyi kullanma becerisini geliştireceği bir öğrenme ortamı yaşamasını sağlayacağı belirtilmektedir (23). NGT beceri uygulamasının klinik öğretimi ve probleme dayalı öğrenmede uygulanmasını kolaylaştırmak için, sistemin başarısız ve zorlu durumlarının öğrencinin karşısına çıkartılması gerektiği ve bu durumun öğrencilerin eleştirel düşünme ve karar verme becerilerini arttırarak klinik ortamlarda deneyimledikleri güçlükleri düzeltme sağlayacağı belirtilmektedir. Şu anda, sanal gerçeklik eğitim sistemi sadece normal NGT yerleştirme koşullarını ve başarılı yerleşimleri simüle etmektedir $(23,27)$.

Geliştirmiş olduğumuz program ile NGT uygulama becerisinin öğretiminde literatürde yer alan boşlukları ve eksiklikleri gidererek etkin NGT öğretiminin gerçekleşmesi amaçlanmaktadır. Programımız haptik kontrollü artırılmış gerçeklik teknolojisi ile gerçeklik hissini yaşatarak özellikle öğrencinin klinik uygulamaya çıkamadığı ve laboratuvar ortamını kullanamadığ durumlarda NGT becerisini geliştirebilecektir. Program; interaktif, görselliği artırılmış $3 \mathrm{D}$, üç boyutlu beceri videolu, animasyonlu, ögrenciler tarafından giyilebilir haptik teknolojiler kullanılarak işlev görmektedir (Resim 1).



Resim 1. NAZO-AR programından bir görüntü kesiti

NGT uygulamasında gerekli tüm adımlar bu eğitim programının içinde görsel, hafızada kalıcı şekilde yazılım ile oluşturulmuştur. Eğitimin temel amacı, NGT becerisi artırılmış gerçeklik teknolojisi ile uygulanarak klinik hemşirelik eğitiminin modifiye edilmesidir. $\mathrm{Bu}$ 
uygulamanın, hemşirelik eğitiminin pedagojisini teori ve klinik olmadan teori, simülasyon ve klinik uygulamaya dönüştürmesi beklenmektedir.

Program sonunda hem eğitimci hem de öğrenci başarı düzeyini, malzeme yönetimini, işlem basamaklarının sırasını, yaptığı hataları, doğru işlem basamaklarını ve uygulama sonrasında gerçekleşebilecek komplikasyonları gerçekte uygular gibi deneyimleyerek beceriyi kazanabilecektir. Ayrıca yetişkin ve çocuğun anatomik yapılarını ayrıntılı görerek uygulama sırasındaki farklılıkları anlayabilecektir. $\mathrm{Bu}$ bilgiler 1şı̆̆ında, programın etkinliğinin araştırmalarla test edilmesi, elde edilen bulgular doğrultusunda revize edilmesi ve diğer yöntemlerle karşılaştırılması planlanmaktadır. Uygulamanın gelecekte tablet ve telefonlarda da çalışır versiyonlarının oluşturulması amaçlanan diğer hedeflerdendir.

\section{SONUÇ}

Bilginin güç, iletişimin ise zorunluluk haline geldiği, bilimsel ve teknolojik değişimlerin çok hızlı yaşandığı günümüzde bireysel ve mesleksel yaşam, değişimin baskısı altında şekillenmektedir. $\mathrm{Bu}$ gelişim ve değişimlere uyum sağlamak için teknolojiden faydalanmak eğitim kurumlarının ve geleceğin meslek üyeleri olan hemşirelik öğrencilerinin, güçlü ve bağımsız olarak gelişmelerini sağlamaktadır. Teknoloji ve bilginin birlikte kullanılarak simülasyon sistematiği ile eğitim verilmesi; yenilikçi, eleştirel düşünme ve karar verme becerisi yüksek hemşirelerin yetişmesini desteklemektedir. Böylece inovasyon kültürü oluşturularak mezun edilen hemşireler, mesleğimizin gelişmesine katkıda bulunacaktır. $\mathrm{Bu}$ nedenle, eğitimde simülasyon kullanımının arttırılması ve hemşirelik uygulamalarının simülasyona temellendirilmesi önerilmektedir. Programımızla hemşirelik eğitimine inovatif bir öğretim metodu kazandırarak öğrencilerin teknoloji ile donatılmasını hedeflemekteyiz.

\section{KAYNAKLAR}

1. Irving SY, Lyman B, Northington L, Bartlett JA, Kemper C. Nasogastric tube placement and verification in children: Review of the current literature. Critical Care Nurse. 2014; 29(3): 267-76.

2. Longo MA. Best evidence: Nasogastric tube placement verification. Journal of Pediatric Nursing. 2011; 26(4): 373-6.

3. Ellett MLC, Cohen MD, Croffie JM, Lane KA, Austin JK, Perkins SM. Comparing bedside methods of determining placement of gastric tubes in children. Journal for Specialists in Pediatric Nursing. 2014; 19(1): 68-79.

4. Kavakli AS, Ozturk NK, Karaveli A, Onuk AA, Ozyurek L, Inanoglu K. Comparison of different methods of nasogastric tube insertion in anesthetized and intubated patients. Revista Brasileira de Anestesiologia. 2017; 67(6): 578-83.

5. Metin ZG, Özdemir L. Yoğun bakımda enteral pompa ile beslenen hastalarda gelişen komplikasyonlar ve etkileyen faktörlerin belirlenmesi. Hacettepe Üniversitesi Hemşirelik Fakültesi Dergisi. 2015; 2(2): $1-10$.
6. Güllüpınar B. Nazogastrik sondanın ölümcül komplikasyonu: Pnömotoraks. İzmir Göğüs Hastanesi Dergisi. 2013; 27(1): 59-63.

7. Resmi Gazete.gov.tr [Internet]. Ankara: Resmi Gazete-Hemşirelik Yönetmeliğinde Değişiklik; 19.04.2011 [Son güncelleme tarihi: 19.04.2011; Erişim tarihi: 06.06.2018]. Erişim adresi: http://www.resmigazete.gov.tr/eskiler/2011/04/201104 19-5.htm.

8. Çelik N. Nazogastrik tüp ve hemşirelik girişimleri. SDÜ Sağlık Bilimleri Dergisi. 2013; 4(2): 75-80.

9. Choi K-S, He X, Chiang VC-L, Deng Z. A virtual reality based simulator for learning nasogastric tube placement. Computers in Biology and Medicine. 2015; 57(1): 103-15.

10. Dil S, Uzun M, Aykanat B. Innovation in nursing education. Journal of Human Sciences. 2012; 9(2): 1217-28.

11. Melnyk BM, Fineout-Overholt E. Evidence-based practice in nursing \& healthcare: A guide to best practice. New York: Lippincott Williams \& Wilkins; 2011.

12. Özel Erkan D. Web Tabanlı Hemşirelik Tanıları Mobil Öğrenme Sistemi [Doktora Tezi]. Antalya: Akdeniz Üniversitesi Sağlik Bilimleri Enstitüsü Biyoistatistik ve Tıp Bilişimi A.D.; 2016.

13. Karadağ $M$, Çalışkan N, İşeri Ö. Simüle hasta kullanımına ilişkin öğrenci görüşleri. Journal of Contemporary Medicine. 2015; 5(1): 36-44.

14. Kim HY, Ko E, Lee ES. Effects of simulation-based education on communication skill and clinical competence in maternity nursing practicum. Korean Journal of Women Health Nursing. 2012; 18(4): 31220.

15. Leonard B, Shuhaibar EL, Chen R. Nursing student perceptions of intraprofessional team education using high-fidelity simulation. Journal of Nursing Education. 2010; 49(11): 628-31.

16. Ann Cordeau M. The lived experience of clinical simulation of novice nursing students. International Journal for Human Caring. 2010; 14(2): 8-14.

17. Berndt J, Dinndorf-Hogenson G, Herheim R, Hoover C, Lanc N, Neuwirth J, et al. Collaborative classroom simulation (CCS): An innovative pedagogy using simulation in nursing education. Nurs Educ Perspect. 2015; 36(6): 401-2.

18. Johansson P, Petersson G, Saveman B-I, Nilsson G. Experience of mobile devices in nursing practice. Vård i Norden. 2012; 32(4): 50-4.

19. Tsai PF, Kitch S, Beck C, Jakobs T, Rettiganti M, Jordan $\mathrm{K}$, et al. Using an interactive video simulator to improve certified nursing assistants' dressing assistance and nursing home residents' dressing performance: A pilot study. Comput Inform Nurs. 2018; 36(4): 183-92.

20. Fairén G, Marta F, Mariona MA. Virtual reality to teach anatomy. In: Jordi I, editor. Annual Conference of the European Association for Computer Graphics; 2017; Barcelona. Lyon: European Association for Computer Graphics (Eurographics) Education Papers; 2017. p. 51-8.

21. Dreesmann N. Virtual Reality check: Are you ready? Journal of Gerontological Nursing. 2018; 44(3): 3-4. 
22. Vidal VL, Ohaeri BM, John P, Helen D. Virtual reality and the traditional method for phlebotomy training among college of nursing students in Kuwait: Implications for nursing education and practice. Journal of Infusion Nursing. 2013; 36(5): 349-55.

23. Chiang VCL, Choi TKS, Ching SSY, Leung KLK. Evaluation of a virtual reality based interactive simulator with haptic feedback for learning NGT placement. Journal of Problem-Based Learning. 2017; 4(1): 25-34.

24. Ferguson C, Davidson PM, Scott PJ, Jackson D, Hickman LD. Augmented reality, virtual reality and gaming: An integral part of nursing. Contemporary Nursing. 2015; 51(1): 1-4.

25. Vaughn J, Lister M, Shaw RJ. Piloting augmented reality technology to enhance realism in clinical simulation. Comput Inform Nurs. 2016; 34(9): 402-5.

26. Carlson KJ, Gagnon DJ. Augmented reality integrated simulation education in health care. Clinical Simulation in Nursing. 2016; 12(4): 123-7.

27. Aebersold M, Voepel-Lewis T, Cherara L, Weber M, Khouri C, Levine $\mathrm{R}$, et al. Interactive anatomyaugmented virtual simulation training. Clinical Simulation in Nursing. 2018; 15(1): 34-41. 